\title{
Meeting the psychiatric needs of children in foster care
}

\author{
Social workers' views
}

Jeannette Phillips

\begin{abstract}
This study sought social workers' views on the mental health needs of a sample of foster children. Out of the sample $\mathbf{8 0 \%}$ of the children were considered to require treatment from a child mental health professional but only $27 \%$ had recelved any input. The reasons given for not refering for treatment were placement instability, inadequate child mental health resources and insulticient local outhority funding. The provision of consultation services to allocated social workers and the avallabillty of child mental health professionals at local authortty reviews should be considered.
\end{abstract}

In the UK there are still large numbers of children in foster care despite the recommendations of the Children's Act (Department of Health, 1993). In March 1993 there were estimated to be 31700 fostered children in England alone (Department of Health and Personal Social Services, 1994). Although children in foster care are at high risk of experiencing a variety of difficulties, there has been long-standing concern that many do not receive the help they require (Kurtz et al, 1994). These unmet needs of foster children are particularly relevant to child mental health professionals because of the increased prevalence of emotional and behavioural difficulties in this group compared to the general population (Rushton et al, 1988; Wolkind \& Rushton, 1994; McCann et al, 1996). As a consequence of professional concern about the difficulties experienced by this group of children, the Department of Health has advised the comprehensive assessment of the foster child's needs at regular intervals (Department of Health, 1995). Although these reviews should include the assessment of emotional and behavioural well-being, they are completed by social workers and there is no requirement for other professionals to be involved. Consequently at present allocated social workers must be able to recognise when foster children have significant mental health needs and be able to obtain appropriate help from child mental health teams. There is a growing concern about the lack of involvement of health services in planning for children and a belief that there needs to be more joint planning between social services and health departments (Sutton, 1995).

This study ascertained social workers' views about the mental health of a clinical sample of foster children and determined whether the children judged to have mental health needs were referred for treatment. Social workers opinions about the efficacy of any mental health interventions were also sought.

\section{The study}

The names of 69 foster children who had been seen at the Maudsley Hospital between 1989 and 1991 for assessment of placement requirements were obtained from computerised records. The identity of the allocated social worker for each child was obtained from the case notes, comprising 26 social workers in total. Correspondence was forwarded to each social worker requesting participation in the study. Two attempts were made to contact the social workers. A positive response was received from 20 social workers $(77 \%)$. The inclusion criteria were that the child was still in care at the time of follow-up and the social worker was allocated to the child currently. Eighteen social workers based in local authorities in the south-east of England were allocated to 44 foster children who matched the inclusion criteria. The sample of children represented $64 \%$ of the original group of 69 foster children referred over the three-year period. The 44 foster children who were the subjects of this study comprised 21 girls and 23 boys, average age 8.3 years.

Each social worker was interviewed about each child in their care using a semi-structured questionnaire that assessed:

(a) The level of perceived symptomatology, using questions based on the Maudsley item sheet (Goodman \& Simonoff, 1991). For a symptom to be coded as present the social workers were required to give 
examples of the abnormal behaviour and to describe how this behaviour adversely interfered with the child's life.

(b) Whether a referral to a child mental health team was indicated, whether a referral had been made and. if not why that decision was taken.

(c) The social workers' opinions of the treatment provided by any child mental health team.

The interviewer was blind to the child's diagnosis and the recommendations arising from the original assessment. This information was obtained from the case notes after interviews with the social workers.

\section{Findings}

Symptomatology and need for treatment

The most frequently reported symptom groups were anxiety, conduct disorder and depression. Only 5 (14\%) of the 44 children were reported to be asymptomatic. Fifty-five per cent of the children were thought to have impairing symptoms of anxiety. Most of these $(45 \%$ of the total sample) had social anxiety, for example anxiety about visitors to the foster home. All the children with anxiety symptoms were anxious that something awful was going to happen to them or their foster families. Two children, both of whom had been sexually abused in a car, had extreme anxiety about getting into cars. Forty-six per cent of the children had impairing externalising behaviours typical of conduct disorder. In the majority this consisted of fighting with biological and/or foster siblings, stealing (particularly food), truanting and being generally destructive. Twenty-three per cent of the children were said to be sufficiently unhappy that activities such as day trips and parties appeared less pleasurable than would be expected. Nearly $20 \%$ had impairing problems with peer relationships. Surprisingly, only $9 \%$ of the children were thought by the social workers to be significantly underachieving at school. Social workers thought that $80 \%$ of the total sample should be receiving therapy of some sort from a mental health professional.

\section{Input from mental health professionals}

The social workers thought that $80 \%(n=35)$ of the children would benefit from treatment from a child mental health team at the time of the interview. At the initial assessment a consultant child psychiatrist had recommended that 22 of these 35 children be offered some form of treatment from a mental health resource. As described below, in fact only 12 children received treatment in the time between the initial assessment and the follow-up study. The psy- chiatrists had recommended the following types of interventions: supportive therapy or counselling, specialised therapy for sexual abuse, psychodynamic psychotherapy, behavioural treatment and family therapy. Two children had been considered to require treatment with antidepressants. At the time of follow-up only 12 individuals $(27 \%)$ from the total sample had received any therapy. Each had been recommended for therapy at the initial assessment. Consequently $53 \%$ of the sample were considered by the social workers to need input from a child mental health team but had not been referred (non-referred cases). Twenty-two per cent of the sample had been assessed by both a child psychiatrist and social worker to require treatment but had not been referred for it.

Three explanations were offered for the failure to seek therapy for the non-referred cases:

(a) In half of the non-referred cases the social workers reported that placement instability was a contraindication to a referral being made. Their experience had been that until the child had a permanent address the child mental health resource would refuse an appointment.

(b) In a quarter of the non-referred cases the social workers did not refer because they were dissatisfied with the mental health facilities available which they considered would fail to meet the child's needs.

(c) In the other quarter of non-referred cases a lack of local authority resources was considered the main explanation for failure to refer.

\section{Treatment provided}

The help provided to the $12(27 \%)$ treated children could be broken down into the following four types; individual psychotherapy, group therapy for child sexual abuse, medication and consultation service. The social workers preferred the consultation service with flexdble appointments for the child to be seen as necessary. They thought that the group therapy had been useful but insufficient. The social workers reported that the individual psychotherapy and the medication helped the recipients but were dissatisfied with the poor communication between the therapists and themselves.

\section{Comment}

Several important issues are raised by this study of a clinical sample of foster children which may be relevant to the general population of children in care. The allocated social workers reported a high level of mental health need, but despite their belief that $80 \%$ of the children should have 
been referred for therapy from a child mental health team, this happened in only $27 \%$ of the sample. Neither the social workers' recognition of the need for therapy nor a prior psychiatric recommendation guaranteed the provision of therapy and were therefore insufficient in themselves. Professionals involved in the care and treatment of foster children should be aware that external factors such as foster placement instability, inappropriate local child mental health resources and insufficient local authority funding may be preventing some of these children's mental health needs being met. Increasing the availability of child mental health professionals at the regular reviews and/or the provision of a consultation service to social workers allocated to foster children might lead to more appropriate treatment of foster children.

The social workers in this study reported a shortage of appropriate treatment resources. Studies are required to evaluate the reality of this perception as far as foster children are concerned. The social workers also reported a shortage of funding for treatment. Consideration should be given to the possibility of ring-fencing money for treatment of children in foster care.

\section{Limitations of the study}

The sample comprised foster children who had previously been assessed at a tertiary referral centre, therefore the results may not be representative of the total population of foster children. This is because children referred to the Maudsley Hospital are a highly selected group representing the foster children who have been recognised by the social workers to be at the highest risk of psychiatric disorder requiring attention from a specialist clinic.

The rate of problems reported in this study is based entirely on information obtained from the social workers, and while they knew the children in their care very well, they may not always have been aware of all the problems. For example the finding that only $9 \%$ of the sample were experiencing problems at school is unlikely to be reliable, based on the reports of other authors (Wolkind \& Rushton, 1995) and suggests that the school and/or the social workers had not recognised the severity of educational difficulties.

There was no control group for this study which means that it is not possible to compare the reported symptomatology rate of the current sample with that of non-fostered children.

\section{Acknowledgement}

The author thanks Dr Anthony Bailey for his time and helpful comments during the preparation of this paper.

\section{References}

DEPARTMENT OF HEALTH (1993) Children in Care of Local Authorities. London: HMSO.

- (1995) Looking after Children: Care plan. London: HMSO.

Department of Health aNd PERsonal Social SERVICEs (1994) Health and Personal Social Services: Statistics for England. London: HMSO.

GOODMAN, R. \& Simonofr, E. (1991) Reliability of clinical ratings by trainee child psychiatrists: a research note. Journal of Child Psychology and Psychiatry. 32. 551-555.

KURTZ, Z., THORNES, R. \& WOLKIND, S. (1994) Services for the Mental Health of Children and Young People in England: A National Review. London: Department of Public Health.

MCCANN, J. B.. James, A. \& Wilson, S. (1996) Prevalence of psychiatric disorders in young people in the care system. British Medical Journal, 313, 1529-1530.

Rushton, A.. TResedar, J. \& QUinton, D. (1988) New Parents for Older Children. London: British Agencies for Adoption and Fostering.

Surton, P. (1995) Crossing the Boundaries: A Discussion of Children's Services Plans. London: National Children's Bureau.

WolkInd, S. \& RUSHTON. A. (1994) Residential and foster family care. In Child and Adolescent Psychiatry. Modem Approaches (eds M. Rutter, E. Taylor \& L. Hersov). pp. 252-266. Oxford: Blackwell Scientific Publications.

Jeannette Phillips, Senior Registrar, Department of Child and Adolescent Psychiatry, Maudsley Hospital, Denmark Hill, London SE5 8AZ 